UDC 303.425.6

LBC 60.524

\title{
SOCIO-ECONOMICAL RISKS OF THE PANDEMIC PERIOD AND PRACTICES TO OVERCOME THEM: GOVERNMENTS' POLICIES AND CITIZENS' STRATEGIES
}

\author{
Nataliya M. Velikaya \\ Institute of Socio-Political Research of the Russian Academy of Sciences, Moscow, Russian Federation; \\ Russian State University for the Humanities, Moscow, Russian Federation
}

Natalia I. Belova

Russian State University for the Humanities, Moscow, Russian Federation

\begin{abstract}
The article is devoted to the reaction of the societies of four countries (the United States, Great Britain, Italy and Russia) to the global risks and challenges associated with the spread of the coronavirus epidemic, which has grown from a health problem to a global political and economic one. Considering the socio-economic risks of the pandemic as the most significant for the lives of citizens of different countries, the authors operationalize them through the fears of public consciousness. The events of the last year have shown that the increased fear and panic among the population in the face of "new infections" has turned into a global problem. The specifics of the life organization in the context of the spread of the pandemic have contributed to the emergence of new distinct socio-economic and socio-political practices that require analysis. The obvious request to the authorities from the population of different countries to ensure the adoption of timely and effective measures to prevent the spread of infection and minimize its consequences also actualize the study of public attitudes during the pandemic in a comparative context. Based on a comparative international online survey, the main socio-economic risks and fears of residents of the four countries were identified, which included both general threats to well-being (low incomes, unemployment, lack of prospects in life, housing problems, etc.) and threats actualized by the pandemic situation (difficulties in obtaining medical care, the high cost of medicines, the inability to go on vacation, difficulties with obtaining education). The differences in satisfaction with the socio-economic situation in the countries, including the response to the actions of governments and local authorities, were analyzed. The review of individual strategies for coping with crisis situations showed significant differences across countries. At the same time, in assessing the activities of the authorities, respondents demonstrate unanimity, showing dissatisfaction with the measures taken and concern for their well-being in the future. The conclusion is made about the actualization of socio-economic fears during the spread of the pandemic and the widespread deterioration of the social well-being of the population.

Key words: social and political risks, social threats, poverty, state policy, citizen's behavior strategies, pandemic COVID-19.

Citation. Velikaya N.M., Belova N.I. Socio-Economical Risks of the Pandemic Period and Practices to ธ్ర Overcome Them: Governments' Policies and Citizens' Strategies. Logos et Praxis, 2021, vol. 20, no. 1, pp. 78-88. (in Russian). DOI: https://doi.org/10.15688/lp.jvolsu.2021.1.9
\end{abstract}


УДК 303.425 .6

ББК 60.524

\title{
СОЦИАЛЬНО-ЭКОНОМИЧЕСКИЕ РИСКИ ПЕРИОДА ПАНДЕМИИ И ПРАКТИКИ ИХ ПРЕОДОЛЕНИЯ: ПОЛИТИКА ГОСУДАРСТВ И СТРАТЕГИИ ГРАЖДАН
}

\author{
Наталия Михайловна Великая \\ Институт социально-политических исследований, Федеральный научно-исследовательский \\ социологический центр РАН, г. Москва, Российская Федерация; \\ Российский государственный гуманитарный университет, г. Москва, Российская Федерация
}

Наталья Ильинична Белова

Российский государственный гуманитарный университет, г. Москва, Российская Федерация

Аннотация. Статья посвящена реакции обществ четырех стран (США, Великобритании, Италии и России) на глобальные риски и вызовы, связанные с распространением эпидемии коронавируса, которая переросла из проблемы здравоохранения в глобальную политическую и экономическую проблему. Рассматривая социально-экономические риски пандемии как наиболее значимые для жизни граждан разных стран, авторы операционализируют их через страхи общественного сознания. События последнего года продемонстрировали, что обострившиеся страх и паника среди населения перед «новыми инфекциями» переросли в глобальную проблему. Специфика организации жизни в условиях распространения пандемии способствовала появлению новых отличных социально-экономических и социально-политических практик, которые требуют анализа. Очевидный запрос к власти со стороны населения разных стран обеспечить принятие своевременных и эффективных мер в распространения инфекции и минимизации ее последствий также актуализируют изучение общественных настроений в период пандемии в сравнительном контексте. На основе сравнительного международного онлайн опроса были выявлены основные социально-экономические риски и страхи жителей четырех стран, которые включали в себя как общие угрозы благополучию (низкие доходы, безработица, отсутствие перспектив в жизни, проблемы с жильем и т. д.), так и угрозы, актуализированные ситуацией пандемии (трудности с получением медицинской помощи, дороговизна лекарственных средств; невозможность уехать в отпуск, сложности с получением образования). Были проанализированы различия в удовлетворенности социально-экономической ситуации в странах, в том числе реакции на действия правительств и местных органов власти. Рассмотрение индивидуальных стратегий преодоления кризисных ситуаций показало существенные различия по странам. При этом в оценках деятельности власти респонденты демонстрируют единодушие, проявляя неудовлетворенность принимаемыми мерами и обеспокоенность своим благополучием в будущем. Сделан вывод об актуализации страхов социально-экономического толка в период распространения пандемии и повсеместном ухудшении социального самочувствия населения.

Ключевые слова: социально-экономические риски, социальные угрозы, бедность, политика государства, стратегии поведения граждан, пандемия COVID-2019.

Цитирование. Великая Н. М., Белова Н. И. Социально-экономические риски периода пандемии и практики их преодоления: политика государств и стратегии граждан // Logos et Praxis. - 2021. - T. 20, № 1. C. 78-88. - DOI: https://doi.org/10.15688/lp.jvolsu.2021.1.9

Еще 20 лет назад в одном из докладов Совета безопасности ООН [Доклад Совета Безопасности ООН... web] экспертами было заявлено, что инфекционные болезни из медицинских проблем переросли в разряд глобальных политических проблем. События последнего года, связанные с коронавирусной инфекции COVID-19 служат тому подтверждением. Пандемия как планетарная международная реаль- ность в которой живут граждане разных стран, еще раз доказывает, что вирусы, вызывающие инфекционные болезни, не признают границ и суверенность государств.

Как заметил Генеральный директор ВО3 по прошествии практически года с момента начала пандемия COVID-19, она стала неожиданностью даже для ряда самых богатых и могущественных стран мира. Она застала 
их врасплох и выявила коллективную неспособность вкладывать ресурсы в обеспечение готовности к чрезвычайным ситуациям [Вступительное слово... web].

Многие эксперты строят крайне неблагоприятные прогнозы и отмечают, что нынешний кризис имеет кардинальные отличия от предыдущих, он уже повлиял на все сферы и отрасли экономики [Романова, Медведева 2020] и внес существенные изменения в повседневную жизнь обычных людей [Белова, Великая, Фадеева 2020, 187]. При этом, правительства различных стран отмечают, что ни один из механизмов и доступных инструментов, применявшихся во время предыдущих экономических кризисов, в нынешней ситуации не способен устранить риски и угрозы, и служить универсальным средством для уверенного экономического ответа на пандемию [Великая, Ирсетская, Великая 2020, 224]. В поиске наиболее приемлемой модели выхода из общемирового кризиса участвуют правительства всех стран мира. Однако для минимизации его последствий требуется международное сотрудничество нового типа, т.к. «только скоординированный международный ответ позволит противостоять новым рискам и бедствиям» [Шеремет 2020, 140].

Выявление социального самочувствия граждан, основанного на оценке социальноэкономической и политической ситуации, особенно в кризисные периоды, такие как пандемии, представляется актуальным. Оно позволяет оценить правильность принятия политических решений, а также определить уровень социальной напряженности и социального самочувствия граждан. В свою очередь, очевидный запрос к власти со стороны населения разных стран обеспечить принятие своевременных и эффективных мер в предотвращении и распространения инфекции и минимизации ее последствий также актуализиру- ют изучение общественных настроений в период пандемии в сравнительном контексте.

В этой связи представляется важным определить не только основные направления антикризисных мер, принимаемых различными государствами, но, прежде всего, выявить оценку гражданами эффективности мер, принимаемых своими правительствами, а также выяснить наиболее распространенные практики преодоления населением социально-экономических проблем в период пандемии.

В основу данной статьи легли результаты онлайн-опроса «Сравнительное социологическое исследование: новые угрозы и практики их преодоления в условиях пандемии» жителей четырех стран (Россия, Великобритания, Италия и США), проведенное в августесентябре 2020 г. методом полуформализованного интервью. Всего было опрошено 1200 жителей, выборочная совокупность строилась квотно-гнездовым методом, где гнездом выступала страна или регион, с соблюдением квоты по полу и возрасту. Опросник для жителей Италии, Великобритании и США был переведен на соответствующий язык ${ }^{1}$.

Общая оценка удовлетворенности ситуацией и жизнью в странах показывает, что угрозы благополучия актуализируются и определяются особенностями экономической ситуации в стране и социально-экономическим положением индивидов: дороговизна жизни, безработица, рост цен, разделение общества на богатых и бедных.

Несмотря на это, более половины граждан в целом удовлетворены своей жизнью. Обратим внимание, что каждый десятый житель Великобритании, США и России говорил о полной неудовлетворенности жизнью в стране. Однако наибольшая доля, высказывающих недовольство и неудовлетворенность жизнью, - это жители Италии (скорее не удовлетворен 39,0 \% и не удовлетворен - 6,0 \%) (см. табл. 1).

Таблий 1

Удовлетворенность жизнью в стране, \%

\begin{tabular}{|l|c|c|c|c|}
\hline \multirow{2}{*}{ Степень удовлетворенности } & \multicolumn{4}{|c|}{ Распределение ответов по странам } \\
\cline { 2 - 5 } & РФ & Вел икобритания & Италия & США \\
\hline Полностью удовлетворен(-а) & $16,7 \%$ & $13,0 \%$ & $7,7 \%$ & $19,3 \%$ \\
\hline Скорее удовлетворен(-а) & $39,3 \%$ & $49,0 \%$ & $45,7 \%$ & $41,3 \%$ \\
\hline Полностью не удовлетворен(-а) & $11,0 \%$ & $11,0 \%$ & $6,0 \%$ & $11,7 \%$ \\
\hline Скорее не удовлетворен(-а) & $29,7 \%$ & $27,0 \%$ & $39,0 \%$ & $25,3 \%$ \\
\hline Затрудняюсь ответить & $3,3 \%$ & $0,0 \%$ & $1,7 \%$ & $2,3 \%$ \\
\hline
\end{tabular}


Среди факторов, которые негативно влияют на социальное самочувствие, осложняют жизнь - проблемы социально-экономического порядка. В первую очередь респондентов беспокоят «низкие доходы, нехватка денег». В максимальной степени проблемой низких доходов обеспокоены россияне (66\% опрошенных). Что касается жителей других стран, то вышеназванной проблемой озабочены чуть более половины жителей Великобритании $(54 \%)$ и более $2 / 5$ граждан Италии и США ( $45 \%$ и $42 \%$ соответственно). Такие ответы лишний раз свидетельствую о наличие общемирового кризиса, когда жители абсолютно всех стран испытывают экономические трудности, не имеют должной материальной поддержки, теряют доходы.

Надо сказать, что по самооценкам в Российской Федерации $42 \%$ жителей не имеют «нормальной работы» и более трети заявляют об отсутствии возможности карьерного роста и перспектив в жизни в общем, более того, по сравнению с жителями других стран, россияне испытывают трудности с выплатами кредитов (пятая часть опрошенных). Прямым подтверждением критической ситуации в финансово-экономическом положении наших граждан являются официальные данные Банка России [Задолженность по кредитам... web]. На протяжении нескольких лет наблю- дается постоянный рост задолженности по банковским кредитам, предоставленным россиянам (физическим лицам - резидентам), однако в период пандемии уровень долга значительно вырос. Так, в сентябре 2020 г., на момент проведения нами опроса, закредитованность населения России была равна 19,2 трлн руб., а годом ранее - 16,9 трлн руб. Обратим внимание, что за пять лет долг граждан перед банками увеличился практически в два раза (сентябрь 2015 г. - 10,4 трлн руб.) [Сведения о задолженности... web]. Возвращаясь к данным нашего опроса отметим, что респонденты из России демонстрируют самый высокий уровень обеспокоенности практически по всем индикаторам: «трудности с получением мед помощи» (39 \%), «невозможность дать детям хорошее образование» $(22 \%)$ и др. (см. табл. 2).

Оценки социально-экономической ситуации на макроуровне - уровне страны, показывают, что подавляющее большинство жителей четырех стран характеризуют экономическую ситуацию как «напряженную, кризисную», а иной раз и как «критическую, взрывоопасную». Прослеживается корреляция между угрозами социально-экономического характера и более высокой оценкой экономических рисков периода пандемии: возможность сокращение доходов и зарплат, потеря работы, сни-

Таблица 2

Распределение ответов на вопрос: «Что особенно осложняет лично Вашу жизнь или жизнь вашей семьи?» (в \% от общего числа опрошенных)

\begin{tabular}{|c|c|c|c|c|}
\hline \multirow{2}{*}{ Варианты ответов } & \multicolumn{4}{|c|}{ Распределение ответов по странам } \\
\hline & $\mathbf{P \Phi}$ & Великобритания & Италия & США \\
\hline Низкие доходы, нехватка денег & $66 \%$ & $54 \%$ & $45 \%$ & $42 \%$ \\
\hline $\begin{array}{l}\text { Отсутствие перспектив в жизни, } \\
\text { невозможность карьерного роста }\end{array}$ & $37 \%$ & $28 \%$ & $24 \%$ & $22 \%$ \\
\hline Отсутствие нормальной работы & $42 \%$ & $23 \%$ & $20 \%$ & $19 \%$ \\
\hline $\begin{array}{l}\text { Невозможность улучшить } \\
\text { жилищные условия }\end{array}$ & $32 \%$ & $26 \%$ & $24 \%$ & $19 \%$ \\
\hline $\begin{array}{l}\text { Трудности с получением } \\
\text { медицинской помощи, дороговизна } \\
\text { лекарственных средств }\end{array}$ & $39 \%$ & $15 \%$ & $17 \%$ & $20 \%$ \\
\hline $\begin{array}{l}\text { Невозможность выйти в отпуск, } \\
\text { отдохнуть }\end{array}$ & $14 \%$ & $25 \%$ & $25 \%$ & $29 \%$ \\
\hline $\begin{array}{l}\text { Отсутствие безопасности на улицах, } \\
\text { в общественных местах }\end{array}$ & $21 \%$ & $20 \%$ & $18 \%$ & $17 \%$ \\
\hline Сложности с выплатой кредитов & $19 \%$ & $13 \%$ & $17 \%$ & $16 \%$ \\
\hline $\begin{array}{l}\text { Очень плохая экология в нашем } \\
\text { городе (районе) }\end{array}$ & $18 \%$ & $15 \%$ & $13 \%$ & $10 \%$ \\
\hline $\begin{array}{l}\text { Невозможность дать детям хорошее } \\
\text { образование }\end{array}$ & $21 \%$ & $10 \%$ & $11 \%$ & $7 \%$ \\
\hline Затрудняюсь ответить & $5 \%$ & $3 \%$ & $6 \%$ & $6 \%$ \\
\hline
\end{tabular}


жение уровня и качества жизни. При этом значимость угроз, связанных с экономическим благополучием, наблюдается в большей степени в России и Италии. Что касается результатов опроса жителей других стран, то в Великобритании 85,6 \% граждан демонстрируют пессимистические взгляды на состояние дел в экономической сфере $(68,3 \%$ - «напряженная, кризисная» и 17,3\% - «критическая, взрывоопасная»). Замыкает четверку результаты ответов граждан Соединенных штатов Америки - 79,3 \% (54,3 и 19,0\% соответственно).

Напомним, что пальму первенства в своеобразном антирейтинге занимает Италия, где основная масса опрошенных $(92,7 \%$ ) дает негативные оценки социально-экономической ситуации в стране («напряженная, кризисная» - 75,0 \% и «критическая, взрывоопасная» $-17,7 \%$ ). На наш взгляд это связано с тем, что Италия, во-первых, одна из первых стран столкнулась с последствиями пандемии коронавируса, а во-вторых, значительную долю ВВП в стране составляет сфера туризма, которая из-за введения ограничений на передвижение за последний год наиболее пострадала. Добавим, что проблема безработицы для Италии остается одной из самых острых на протяжении уже нескольких лет. На момент проведения опроса уровень безработицы в стране был равен 9,5\%, а годом ранее, в сентябре 2019 г. - 9,7 \% [Италия - Общая... web].

В свою очередь ситуация в России выглядит следующим образом: 86,4 \% озабочены экономической ситуацией в стране и характеризуют ее, как «напряженную, кризисную» $(68,7 \%)$ или «критическую, взрывоопасную» (17,7 \%). По данным Сбербанка (лаборатория «СберДанные»), являющегося лидером на рынке зарплатных проектов, в 2020 г. наблюдается снижение фонда оплаты труда (ФОТ) [Изменение объема ФОТ... web] по всем отраслям экономики. При этом наибольшее сокращение ФОТ фиксируется в первые месяцы введенного Lockdown (март-май 2020). В этот период снижена заработная плата $75 \%$ россиян, работающих в основных отраслях экономики. Эксперты [Гордеев, Старостина... web] обращают внимание, что работодатели использовали различные формы сокращения ФОТ, позволившие сохранить численность работников: урезание стимулирующей и основной части заработной платы, перевод части сотрудников на неполный рабочий день либо в неоплачиваемый отпуск. Тем не менее, к сентябрю 2020 г. практически 4,8 млн россиян (6,3 \% всей рабочей силы) [Занятость и безработица... web] оказались безработными. Рост произошел, прежде всего, за счет уволенных в период пандемии. В наиболее уязвимом (прекаризованном) положении оказались неквалифицированные рабочие и люди с невысокими заработками. Поэтому становится понятным, что «увеличение социально-экономической дистанции между богатыми и бедными...на фоне пандемии особенно ярко иллюстрирует ситуация в России» [Шеремет 2020, 140].

Ввиду того, что ухудшение социальноэкономической ситуации наблюдается во всех странах, нам представлялось крайне важным выяснить самооценку уровня благополучия отдельных индивидов и семей. Самые низкие оценки, связанные с уверенностью в защищенности от потенциальных экономических кризисов оказалась у респондентов из России $(44,3 \%)$. Наиболее уверенно в завтрашний день, с экономической точки зрения, смотрят практически четверть жителей США (23,0 \%) и, как ни парадоксально, Италии (24,3 \%), которые отметили, что высоко оценивают свою защищенность (см. табл. 3).

Заметим, что управление ситуацией, связанной с распространением коронавирусной инфекции, потребовало от политической власти

Таблииа 3

Оценка респондентами степени своей защищенности от возможных экономических потрясений и кризисов, \%

\begin{tabular}{|l|c|c|c|c|c|}
\hline \multirow{2}{*}{ Степень защищенности } & \multicolumn{3}{|c|}{ Распределение ответов по стран ам } & \\
\cline { 2 - 6 } & $\mathbf{P Ф}$ & Великобритания & Италия & США & Общий итог \\
\hline Высокая & $6,0 \%$ & $14,7 \%$ & $\mathbf{2 4 , 3 \%}$ & $\mathbf{2 3 , 0 \%}$ & $17,0 \%$ \\
\hline Средняя & $45,7 \%$ & $\mathbf{6 1 , 0 \%}$ & $55,3 \%$ & $51,3 \%$ & $53,3 \%$ \\
\hline Низкая & $\mathbf{4 4 , 3 \%}$ & $21,0 \%$ & $17,7 \%$ & $19,0 \%$ & $25,5 \%$ \\
\hline Затрудняюсь ответить & $4,0 \%$ & $3,3 \%$ & $2,7 \%$ & $6,7 \%$ & $4,2 \%$ \\
\hline
\end{tabular}


разработки и принятия целого комплекса мер в самых различных сферах, которые носили как ограничительный, так и поддерживающий, стимулирующий характер. По мнению отдельных экспертов, «...Никто не мог предположить, что государства, как политическая форма организации обществ, способны сформировать новую (хотя и временную) экономическую поведенческую модель...Такое связанное с не экономическими причинами критическое падение спроса и предложения, обусловленное масштабным государственным вмешательством в рыночные механизмы, произошло впервые в новейшей истории мирового хозяйства» [Белов 2020, 5].

Анализ источников позволяет выделить наиболее распространенные социально-экономические меры, которые использовали правительства разных стран (Италия [COVID-19, Misure... web], Великобритания [Coronavirus: UK... web; Chancellor's statement... web] и США [Cochrane, Fandos... web]):

- во-первых, это меры по поддержке национальных систем здравоохранения, а также других субъектов, участвующих в оказании медицинской помощи и борьбе с эпидемией;

- во-вторых, широкий спектр мер, направленных на поддержку уровня жизни и платежеспособности семей (Италия), в том числе в виде прямых выплат гражданам, включая дополнительные выплаты на детей (США);

- в-третьих, это программы государственного кредитования, гарантированные займы (США) и денежные гранты для самозанятых (Великобритания) малым предприятиям и малому бизнесу, а также поддержка компаний с целью предотвращения безработицы, в том числе секторальная поддержка (например, поддержка индустрии туризма (Италия));

- в-четвертых, различные налоговые меры для населения и бизнеса.

Что касается Российской Федерации, то наиболее значимыми и продуктивными мерами поддержки были следующие: финансовая поддержка некоторых отраслей промышленности [Федеральный закон от 08.06.2020... web; Постановление Правительства РФ от 24.04.2020... web], меры в области социальной поддержки врачей, предусматривающие дополнительные выплаты медицинским ра- ботникам, работающим в красной зоне; меры социальной поддержки детей и родительства. Так, дополнительные меры материального характера для домохозяйств, где проживают дети от 3 до 7 лет должна была начать действовать с июля 2020 г., однако В. Путин распорядился ускорить процесс и начать выплаты семьям с июня 2020 г. [Обращение к гражданам... web].

При этом респонденты проявили удивительное единодушие в плане оценки деятельности своих правительств по поддержке бизнеса и граждан. Практически по всем позициям треть опрашиваемых дают среднюю оценку «мерам социально-экономической поддержки населения» - «3 - удовлетворительно»: от 28,0 \% (поддержка работников и компаний с целью предотвращения безработицы) до 33,0 \% (мораторий на налоги для малого и среднего бизнеса). Напомним, что самооценка собственных социально-экономических проблем, намного выше среднего, чем оценки проводимой политики по предоставлению мер поддержки. Косвенно это может свидетельствовать либо о том, что среди наших опрошенных крайне мало тех, кто относится к лицам, попавшим в трудную жизненную ситуацию и нуждающихся в мерах социальной поддержки, либо наблюдается общемировая проблема - невозможность или нежелание правительств решать проблемы своих граждан. Немного, но все-таки большее количество респондентов, оценивают практики конкретных государств мира по поддержке граждан и бизнеса (малого и среднего), в связи с пандемией коронавируса, на «3 (удовлетворительно)».

Учитывая, что меры, принимаемые государственными органами зачастую носили не только стимулирующий и поддерживающий характер, но и ограничительный, общество довольно неоднозначно реагировало на эти инициативы, что подтверждается и данными других исследований [Ashraf web].

Опрос показал, что более половины жителей Великобритании $(63,7 \%)$ и США $(50,3 \%)$ склоняются к тому, что действия властей страны по борьбе с вирусом недостаточны, а в Италии и России, напротив, значительное количество людей считают, что были приняты все необходимые меры (49,0 и 39,3 \% 
соответственно), и частично даже избыточные (7,7 и $18,0 \%$ соответственно). Россияне в этом контексте продемонстрировали максимальное неудовольствие в связи с избыточностью мер, что как известно, сопровождалось, повсеместным нарушением масочного режима.

Похожая ситуация наблюдается и в оценках действий властей региона, здесь также результаты демонстрируют определенный раскол. В США и Италии мнения поделились практически поровну: 41,7 \% жителей Америки говорят о достаточности принятых мер, что все необходимые меры были приняты, а 42,7 \% утверждают, что они были недостаточны. Такая же картина и в Италии: 45 \% против 44,7 \%. В России же пятая часть придерживается мнения, что региональная и местная власть приняла слишком жесткие и ненужные меры (21,7 \%), а вот четвертая часть, напротив, думает, что принятые меры недостаточны.

Имеет смысл остановится и на международном контексте пандемии, в частности, усилиях международных организаций в плане выработки консолидированных действий и оказания помощи другим странам.

Наш опрос не выявил особой дифференциации в ответах респондентов по странам при оценке эффективности работы международных организаций по профилактике и минимизации последствия пандемии, что во многом было связано и с запаздывающими стратегиями названных организаций, и с их устойчиво-негативным медиа-образом (см. табл. 4).

Безусловно, «удовлетворенность жизнью в стране» как индикатор социального самочувствия, может свидетельствовать о латентных, но достаточно серьезных дезинтеграционных, порой даже деструктивных процессах. Он тесно связан с другим показателем социального самочувствия - оценкой своего будущего. Так, наименьшую уверенность в завтрашнем дне высказали жители Италии и России. Наиболее уверены в своем будущем, в завтрашнем дне респонденты из США (см. табл. 5).

Очевидно, что нестандартная, кризисная пандемическая ситуация вызывала целую серию «страхов», которые определяли и социально-психологическое самочувствие населения, и выработку определенных стратегий преодоления возможных трудностей. По результатам опроса выделены 3 группы «страхов будущего»: экономические, социально-направленные и связанные со здоровьем.

Таблииа 4

Оценка эффективности работы международных организаций
по профилактике и минимизации последствий пандемии коронавируса
по пятибалльной шкале, средний балл
\begin{tabular}{|l|c|c|c|c|}
\hline \begin{tabular}{|} 
Перечень Международных \\
организаций
\end{tabular} & \multicolumn{4}{|c|}{ Средний балл по странам } \\
\cline { 2 - 5 } & РФ & \multicolumn{2}{|c|}{ Великобритания } \\
\hline $\begin{array}{l}\text { Организация объединенных } \\
\text { наций (ООН) }\end{array}$ & 3,0 & 2,8 & 2,7 & 2,8 \\
\hline $\begin{array}{l}\text { Всемирная организация } \\
\text { здравоохранения (ВОЗ) }\end{array}$ & 3,0 & 3,0 & 2,9 & 3,0 \\
\hline $\begin{array}{l}\text { Международный } \\
\text { чрезвычайный детский фонд } \\
\text { ООН (ЮНИСЕФ) }\end{array}$ & 2,9 & 2,8 & 2,8 & 2,8 \\
\hline $\begin{array}{l}\text { Международная организация } \\
\text { труда (МОТ) }\end{array}$ & 2,8 & 2,7 & 2,7 & 2,8 \\
\hline
\end{tabular}

Уверенность в завтрашнем дне, \%

\begin{tabular}{|l|c|c|c|c|}
\hline \multirow{2}{*}{$\begin{array}{c}\text { Варианты ответов на вопрос } \\
\text { «увствуете ли Вы уверенность } \\
\text { в завтрашнем дне» }\end{array}$} & \multicolumn{4}{|c|}{ Распределение ответов по странам } \\
\cline { 2 - 5 } & $\mathbf{P Ф}$ & Великобритания & Италия & США \\
\hline Да & $3,7 \%$ & $11,0 \%$ & $4,3 \%$ & $22,7 \%$ \\
\hline Скорее да & $28,0 \%$ & $34,3 \%$ & $18,0 \%$ & $39,7 \%$ \\
\hline Нет & $25,0 \%$ & $20,0 \%$ & $19,7 \%$ & $13,3 \%$ \\
\hline Скорее нет & $38,7 \%$ & $30,3 \%$ & $49,0 \%$ & $19,3 \%$ \\
\hline Затрудняюсь ответить & $4,7 \%$ & $4,3 \%$ & $9,0 \%$ & $5,0 \%$ \\
\hline Общиий итог & $100,0 \%$ & $100,0 \%$ & $100,0 \%$ & $100,0 \%$ \\
\hline
\end{tabular}


В контексте нашей статьи обратим внимание лишь на «экономические страхи». Из всего перечня возможных событий и явлений, связанных с пандемией коронавируса и относящихся к экономическим, жителей всех стран больше всего тревожит высокая инфляция (52 \%), потеря работы (51\%) и потеря сбережений (50\%). Отметим, что у россиян более выражено проявились экономические страхи, связанные с сокращением заработной платы и потерей работы (по 58 \%), однако лидерами являются страх «высокой инфляции, роста цен $(65 \%)$ и потери сбережений, накоплений $(61 \%)$. На наш взгляд это может быть связано с тем, что многие уже потеряли работу или часть своих доходов, что отображено выше.

При этом в вопросе о действиях респондентов в случае ухудшения материального положения семьи, именно граждане Российской Федерации показали наибольшую готовность к поиску новой работы или подработки $(37 \%)$, в то время как в Великобритании и Италии люди более склонны к экономии на продуктах, услугах и удовольствиях. Третьей стратегией выбрана - трата накоплений, сбережений, однако количество россиян, выбравших этот ответ, практически вдвое меньше, чем жителей других стран: Великобритания (21\%), Италия (19\%), США (16,9\%) и Россия $(10 \%)$, что вполне закономерно, учитывая объемы накоплений российских граждан и количество населения, имеющего эти накопления (см. табл. 6).

Надо сказать, что россияне вообще более пессимистично настроены и выбирают те варианты, которые наименее популярны у жителей зарубежных стран. Вот какие стратегии выхода из сложного экономического положения, хоть и не являющиеся топовыми, свойственны именно нашим гражданам: «ничего не будут предпринимать» $-6,7$ \%, «буду участвовать в митингах, демонстрациях»$8,0 \%$, «рассмотрю варианты эмиграции (уеду из страны)»-10,3\%.

В заключении отметим, что на момент проведения исследования каждый десятый $(13,0 \%)$, участвовавший в нашем опросе (сам либо близкие родственники), столкнулся с инфицированием COVID-2019. При этом страх заразиться наиболее актуален был для жителей Италии и США. Что касается россиян, то практически четверть (24 \%) были совершенно не обеспокоены возможностью заразиться и заболеть. При этом практически пятая часть граждан, как россиян, так и других стран, указали на сложность с получением медицинской помощи. Но все же половина участников опроса к наиболее значимым проблемам периода пандемии отнесли социально-экономические - низкие доходы и нехватка денежных средств; каждый четвертый указал на отсутствие нормальной работы, а каждый пятый на сложности с выплатой кредитов.

Хотя уровень тревожности и различается по странам, максимальное беспокойство везде вызывают проблемы социально-экономического плана, связанные с повседневной жизнью семьи, с возможностью благополучного будущего себя и детей, с ухудшением экономической ситуации в условиях пандемии.

Поведенческие стратегии при ухудшении материального положения, \%

\begin{tabular}{|l|c|c|c|c|}
\hline \multirow{2}{*}{ Варианты ответов } & \multicolumn{4}{|c|}{ Распределение ответов по странам } \\
\cline { 2 - 5 } & РФ & Великобритания & Италия & США \\
\hline $\begin{array}{l}\text { Пытаться искать новую работу, } \\
\text { подрабатывать где-то еще }\end{array}$ & $37,0 \%$ & $17,3 \%$ & $23,3 \%$ & $24,3 \%$ \\
\hline $\begin{array}{l}\text { Экономить на продуктах, отказывать } \\
\text { себе в некоторых удовольствиях }\end{array}$ & $24,0 \%$ & $34,3 \%$ & $31,3 \%$ & $25,0 \%$ \\
\hline Участвовать в митингах, демонстрациях & $8,0 \%$ & $2,0 \%$ & $3,7 \%$ & $2,3 \%$ \\
\hline $\begin{array}{l}\text { Потихоньку начну тратить свои } \\
\text { сбережения (то, что отложил на «черный } \\
\text { день») }\end{array}$ & $10,0 \%$ & $21,0 \%$ & $19,0 \%$ & $17,7 \%$ \\
\hline $\begin{array}{l}\text { Ничего предпринимать не буду - это } \\
\text { бесполезно }\end{array}$ & $6,7 \%$ & $4,0 \%$ & $5,0 \%$ & $6,7 \%$ \\
\hline $\begin{array}{l}\text { Рассмотрю варианты эмиграции (уеду из } \\
\text { страны) }\end{array}$ & $10,3 \%$ & $4,3 \%$ & $8,3 \%$ & $5,0 \%$ \\
\hline Затрудняюсь ответить & $3,3 \%$ & $4,3 \%$ & $4,0 \%$ & $6,3 \%$ \\
\hline Другое (запишите) & $0,7 \%$ & $1,0 \%$ & $0,3 \%$ & $0,7 \%$ \\
\hline
\end{tabular}


Несмотря на существенное ухудшение социально-психологического самочувствия, общество демонстрирует высокую способность адаптации к кризисным ситуациям: появились и закрепились новые социальные практики, оформились новые социальные нормы, выявились разные стратегии преодоления социально-экономических проблем на индивидуальном уровне.

Спустя полгода после начала эпидемии, респонденты невысоко и неоднозначно оценивали усилия органов власти и эффективность принятых мер. Негативные последствия для экономики и социальной жизни проявились и в обострении социального неравенства, и в нарушении социальных взаимодействий, и в повышении уровня социально-политической тревожности.

На фоне сохраняющейся лояльности к власти, более заметным становится запрос обеспечить принятие адекватных мер, чтобы с одной стороны, предотвратить распространение коронавирусной инфекции, исключив ограничения прав и свобод граждан, а с другой, минимизировать экономические риски и социальные последствия пандемии.

\section{ПРИМЕЧАНИЕ}

\begin{abstract}
${ }^{1}$ Инициативный международный опрос «Сравнительное социологическое исследование: новые угрозы и практики их преодоления в условиях пандемии» Авторский коллектив под научным руководством проф. Н.М. Великой (Центр социологических исследований РГГУ). Межстрановый полуформализованный онлайн-опрос проведен в августе - сентябре 2020 года. Было опрошено 1200 жителей четырех стран: Великобритании, Италии, РФ и США. Выборочная совокупность строилась квотно-гнездовым методом, где гнездом выступала страна или регион, с соблюдением квоты по полу и возрасту. Опросник для жителей Италии, Великобритании и США был переведен на соответствующий язык.
\end{abstract}

\section{СПИСОК ЛИТЕРАТУРЫ}

Белов 2020 - Белов В.Б. COVID-19 - Game Changer европейской экономики? // Научно-аналитический вестник ИЕ РАН. 2020. № 3. С. 4-12.

Белова, Великая, Фадеева 2020 - Белова Н.И., Великая Н.М., Фадеева Е.В. Социальные страхи россиян в условиях пандемии коронавирусной инфекции COVID-19 // I Российско-Иранский социологический форум: сб. тез. докл. участников форума (г. Москва, 16-18 ноября 2020 г.) / отв. ред. С В. Рязанцев, Т.К. Ростовская; ФНИСЦРАН. М.: ИТД «ПЕРСПЕКТИВА». 2020. C. 186-196.

Великая, Ирсетская, Великая 2020 - Великая Н.М., Ирсетская Е.А., Великая Т.В. Особенности политического дискурса в период пандемии / I Российско-Иранский социологический форум: сб. тез. докл. участников форума (г. Москва, 16-18 ноября 2020 г.) / отв. ред. С.В. Рязанцев, Т.К. Ростовская; ФНИСЦРАН. М.: ИТД «ПЕРСПЕКТИВА». 2020. С. 224-236.

Вступительное слово... web - Вступительное слово Генерального директора ВОЗ на 148-й сессии Исполнительного комитета. 18.01.2021 // https://www.who.int/ru/director-general/ speeches/detail/who-director-general-sopening-remarks-at-148th-session-of-theexecutive-board

Гордеев, Старостина... web - Гордеев B., Старостина Ю. Сбербанк зафиксировал падение зарплат у половины работающих россиян. Фонд оплаты труда резко сократился из-за последствий пандемии COVID-19. 10.07.2020// https://www.rbc.ru/economics/10/07/2020/ 5f085bc89a794796d50c3017.

Доклад Совета Безопасности ООН 16 июня 2000 года... web - Доклад Совета Безопасности 16 июня 2000 года - 15 июня 2001 года. Генеральная Ассамблея. Официальные отчеты. Пятьдесят шестая сессия Дополнение No 2 (А/ 56/2) // https: undocs.org/ru/A/56/2(SUPP).

Задолженность по кредитам... web- Задолженность по кредитам, предоставленным физическим лицам-резидентам. Официальный сайт банка России // https://cbr.ru/statistics/table/ $? \mathrm{dt}=20190101 \&$ tableid $=4-5$.

Занятость и безработица... web - Занятость и безработица в Российской Федерации в сентябpe 2020 года. Официальный сайт Федеральной службы государственной статистики // https://rosstat.gov.ru/bgd/free/B09_03/ IssWWW.exe/Stg/d05/200.htm.

Изменение объема ФОТ... web - Изменение объема ФОТ. Сайт СберИндекс // https:// www.sberindex.ru/ru/dashboards/izmenenieobema-fot?partition $=6$.

Италия - Общая... web - Италия - Общая численность безработных. Trading Economics // https://ru.tradingeconomics.com/italy/ unemployed-persons.

Обращение к гражданам... web - Обращение к гражданам России президента РФ (23.06.2020). 
Официальный сайт Президента России // http:// www.kremlin.ru/events/president/transcripts/ 63548.

Постановление Правительства РФ... web-ПостановлениеПравительства РФ от 24.04.2020 № 576 «Об утверждении Правил предоставления в 2020 году из федерального бюджета субсидий субъектам малого и среднего предпринимательства, ведущим деятельность в отраслях российской экономики, в наибольшей степени пострадавших в условиях ухудшения ситуации в результате распространения новой коронавирусной инфекции» // https:/www.garant.ru/ products/ipo/prime/doc/73855337.

Романова, Медведева 2020 - Романова Г.Г., Медведева П.И. Состояние различных сфер экономики в период всемирной пандемии //Актуальные вопросы современной экономики. 2020. № 5. C. 219-227.

Сведения о задолженности... web - Сведения о задолженности по кредитам, предоставленным кредитными организациями физическим лицамрезидентам [ЕМИСС Государственная статистика]// https://www.fedstat.ru/indicator/42861\#.

Федеральный закон от 08.06.2020 ... web - Федеральный закон от 08.06.2020 № 172-Ф3 (ред. от $29.12 .2020)$ «О внесении изменений в часть вторую Налогового кодекса Российской Федерации» // http://www.consultant.ru/document/ cons_doc_LAW_354470.

Шеремет 2020 - Шеремет А.Н. Пандемия неравенства. Социально-экономические аспекты и последствия COVID-19 // Медицина. Социология. Философия. Прикладные исследования. 2020. № 4. С. 136-141.

Ashrafweb-AshrafB.N. Economic impact of government interventions during the COVID-19 pandemic: International evidence from financial markets [Journal of behavioral and experimental finance. 2020. Vol. 27] // https://www.sciencedirect.com /science/article/abs/pii/S2214635020302422 https://doi.org/10.1016/j.jbef.2020.100371.

Cochrane, Fandos web - Cochrane E., Fandos T. Senate Approves \$2 Trillion Stimulus After Bipartisan Deal // The New York Times, 05.05.2020// https://www.nytimes.com/2020/03/ 25/us/politics/coronavirus-senate-deal.html.

Coronavirus: UK... web - Coronavirus: UK government unveils aid for self-employed // BBCNews. 26.03.2020 //https://www.bbc.com/news/uk-52053914.

COVID-19, Misure... web - COVID-19, Misure Straordinarie Per La Tutela Della Salute E Il Sostegno All'economia. Governo Italiano Presidenza del Consiglio dei Ministri // http:// www.governo.it/it/articolo/comunicato-stampadel-consiglio-dei-ministri-n-37/14324.
Chancellor's statement... web - Chancellor's statement on coronavirus (COVID-19). 26 March 2020. Coronavirus press conference 26 March 2020 // https://www.gov.uk/government/speeches/ chancellor-outlines-new-coronavirus-supportmeasures-for-the-self-employed.

\section{REFERENCES}

Belov V.B., 2020. COVID-19 - Game Changer of European economy. Nauchno-analiticheskiy vestnik Instituta Yevropy RAN, no. 3. pp. 4-12.

Belova N.I., Velikaya N.M., Fadeeva E.V., 2020. Social fears of Russians in the conditions of the pandemic COVID-19. Ryazantsev S.V. (ed.), Rostovskaya T.K. (ed.). I Rossiysko-Iranskiy sotsiologicheskiy forum: sb. tez. dokl. uchastnikov foruma (g. Moskva, 1618 noyabrya 2020 g.). FNISTS RAN. Moscow, ITD «PERSPEKTIVA», 2020, pp. 186-196.

Velikaya N.M., Irsetskaya E.A., Velikaya T.V., 2020. Features of political discourse during the Pandemic. Ryazantsev S.V. (ed.), Rostovskaya T.K. (ed.). I Rossiysko-Iranskiy sotsiologicheskiy forum. Sbornik tezisov dokladov uchastnikov foruma (g. Moskva, 16-18 noyabrya 2020 g.). FNISTS RAN. Moscow, ITD «PERSPEKTIVA», 2020, pp. 224-236.

WHO Director-General's opening remarks at $148^{\text {th }}$ session of the Executive Board. 18.01.2021. URL: https://www.who.int/director-general/speeches/ detail/who-director-general-s-opening-remarksat-148th-session-of-the-executive-board.

Gordeev V., Starostina U. Sberbank commited salaries declining of the half of employing Russians. Wages Fund was reduced because of consequences of COVID-19 Pandemic 10.07.2020. URL: https://www.rbc.ru/economics/ 10/07/2020/5f085bc89a 794796d50c3017.

Report of the Security Council 16 June 2000-15 June 2001 General Assembly Official Records Fiftysixth Session Supplement no. 2 (A/56/2). URL: https://undocs.org/en/A/56/2(SUPP).

Credit indebtedness granted to resident individuals. Official Website of Bank of Russia. URL: https://cbr.ru/statistics/table/ $? \mathrm{dt}=20190101 \&$ tableid $=4-5$.

Employment and unemployment in the Russian Federation in September 2020. Official website of the Federal State Statistics Service. URL: https://rosstat.gov.ru/bgd/free/B09_03/ IssWWW.exe/Stg/d05/200.htm.

Changing of Wage Fund. Official Web-site of Sberbank. URL: https://www.sberindex.ru/ru/ dashboards/izmenenie-obema-fot?partition $=6$. 
Total unemployment in Italy. Trading Economics. URL: https://ru.tradingeconomics.com/italy/ unemployed-persons.

President's address to the citizens (23.06.2020) Official website of the President of Russia. URL: http:// www.kremlin.ru/events/president/transcripts/63548.

Resolution of the Government of the Russian Federation from 24.04.2020 No. 576 "On approval of Rules of granting subsidies from the Federal budget to small and medium-sized businesses, leading operations in sectors of the Russian economy, the worst affected in the deteriorating situation with the spread of a new coronavirus infection in 2020”. URL: https:// www.garant.ru/products/ipo/prime/doc/ 73855337.

Romanova G.G., Medvedeva P.I., 2020. State of different spheres of economy during world pandemic. Aktual'nyye voprosy sovremennoy ekonomiki, no. 5, pp. 219-227.

Information about credit indebtedness granted to resident individuals by credit organization. EMISS. Federal Statistics. URL: https:// www.fedstat.ru/indicator/42861\#юEmployment and unemployment in the Russian Federation in September 2020. Official website of the Federal State Statistics Service. URL: https:// rosstat.gov.ru/bgd/free/B09_03/IssWWW.exe/ Stg/d05/200.htm.

Federal law of 08.06.2020 № 172-FZ (ed. from 29.12.2020) "On amendments to part two of the Tax code of the Russian Federation». URL: http://www.consultant.ru/document/cons_ doc LAW 354470.

Sheremet A.N., 2020. Pandemic of inequality. Socioeconomical aspects and consequences of COVID-19. Meditsina. Sotsiologiya. Filosofiya. Prikladnyye issledovaniya, no 4, pp. 136-141.

Ashraf B.N., 2020. Economic impact of government interventions during the COVID-19 pandemic: International evidence from financial markets. Journal of behavioral and experimental finance, 2020, vol. 27. URL: https://www. sciencedirect.com/science/article/abs/pii/ S2214635020302422.

Cochrane E., Fandos T., 2020. Senate Approves \$2 Trillion Stimulus After Bipartisan Deal. The New York Times, 05.05.2020. URL: https:// www.nytimes.com/2020/03/25/us/politics/ coronavirus-senate-deal.html.

Coronavirus: UK government unveils aid for selfemployed. BBC News, 26.03.2020. URL: https:// www.bbc.com/news/uk-52053914.

COVID-19, Misure Straordinarie Per La Tutela Della Salute E Il Sostegno All'economia. Governo Italiano Presidenza del Consiglio dei Ministri. URL: http://www.governo.it/it/articolo/comunicatostampa-del-consiglio-dei-ministri-n-37/14324.

Chancellor's statement on coronavirus (COVID-19): 26 March 2020. Coronavirus press conference 26 March 2020. URL: https://www.gov.uk/ government/speeches/chancellor-outlines-newcoronavirus-support-measures-for-the-selfemployed.

\section{Information About the Authors}

Nataliya M. Velikaya, Doctor of Sciences (Politics), Professor, Deputy Director for Science, Institute of Socio-Political Research of the Russian Academy of Sciences, Fotievoy St, 6, Bld. 1, 119333 Moscow, Russian Federation; Dean, Sociology Faculty, Russian State University for the Humanities, Miusskaya Sq., 6, GSP-3, 125993 Moscow, Russian Federation, natalivelikaya@gmail.com, https://orcid.org/0000-0001-5532-844X

Natalia I. Belova, Candidate of Sciences (Sociology), Associate Professor, Department of Applied Sociology, Russian State University for the Humanities, Miusskaya Sq., 6, GSP-3, 125993 Moscow, Russian Federation, n.i.belova@mail.ru, https://orcid.org/0000-0002-0336-7145

\section{Информация об авторах}

Наталия Михайловна Великая, доктор политических наук, профессор, заместитель директора по науке, Институт социально-политических исследований, Федеральный научно-исследовательский социологический центр РАН, ул. Фотиевой, 6, корпус 1, 119333 г. Москва, Российская Федерация; декан социологического факультета, Российский государственный гуманитарный университет, Миусская площадь, 6, 1125993, ГСП-3 г. Москва, Российская Федерация, natalivelikaya@gmail.com, https://orcid.org/0000-0001-5532-844X

Наталья Ильинична Белова, кандидат социологических наук, доцент, доцент кафедры прикладной социологии, Российский государственный гуманитарный университет, Миусская площадь, 6, 1125993 , ГСП-3 г. Москва, Российская Федерация, n.i.belova@mail.ru, https://orcid.org/0000-0002-0336-7145 